\title{
Gender disparities in top earnings: measurement and facts for Denmark 1980-2013
}

\author{
Niels-Jakob Harbo Hansen ${ }^{1} \cdot$ Karl Harmenberg $^{2}$ • Erik Öberg $^{3}$. \\ Hans Henrik Sievertsen ${ }^{4}$
}

Received: 30 September 2019 / Accepted: 21 December 2020 / Published online: 11 March 2021

(C) The Author(s) 2021

\begin{abstract}
Extending the work of Atkinson et al. (J. Econ. Inequal. 16, 225-256, 2018), we decompose top-earnings gender disparities into a glass-ceiling coefficient and a top-earnings gender gap. The decomposition uses that both male and female top earnings are Pareto distributed. If interpreting top-earnings gender disparities as caused by a female-specific earnings tax, the top-earnings gender gap and glass-ceiling coefficient measure the tax level and tax progressivity, respectively. Using Danish data on earnings, we show that the top-earnings gender gap and the glass-ceiling coefficient evolve differently across time, the life cycle, and educational groups. In particular, while the top-earnings gender gap has been decreasing in Denmark over the period 1980-2013, the glass-ceiling coefficient has been remarkably stable.
\end{abstract}

Keywords Decomposition · Gender gap · Glass ceiling · Summary statistics

\section{Introduction}

Since several decades back, women's attachment to the labor market has gradually increased across most developed countries (Blau and Kahn 2008; Polachek et al. 2015). This is

Erik Öberg

erik.oberg@nek.uu.se

Niels-Jakob Harbo Hansen

nhansen@imf.org

Karl Harmenberg

kha.eco@cbs.dk

Hans Henrik Sievertsen

h.h.sievertsen@bristol.ac.uk

1 International Monetary Fund, 700 19th St NW, Washington, DC 20431, USA

2 Department of Economics, Copenhagen Business School, Porcelænshaven 16A, 2000 Frederiksberg, Denmark

3 Department of Economics, Uppsala University, Box 513, Uppsala 751 20, Sweden

4 School of Economics, University of Bristol, Priory Road 12, Bristol, BS8 1TU, UK 
also true in Denmark, as displayed in Fig. 1: since 1980, women are to a greater extent participating in the labor market (1a), working full-time jobs (1b), and graduating from career-oriented educational degrees (1c). ${ }^{1}$ As is also well known, this development has been accompanied with a gradual reduction of the average gender earnings gap (1d).

Less is known about the development of gender disparities at the top of the earnings distribution. Although it is known that women are underrepresented at the top, there is no general agreement on how to quantify this under-representation ${ }^{2}$, and, perhaps as a consequence, there is a lack of generally recognized "stylized facts" regarding its development across countries over time. In this paper, we propose a method for measuring top-earnings gender disparities and use it to provide a set of facts for Denmark over the period $1980-2013 .^{3}$

Understanding gender disparities at the top of the earnings distribution is important for several reasons. First, in most countries, earnings are very unequally distributed, meaning that the top part of the distribution accounts for a large share of total earnings (Atkinson et al. 2011; Roine and Waldenström 2015). In consequence, understanding the disparities at the top is important for understanding the overall earnings inequality between men and women. Second, to the extent that gender disparities in earnings are indicators of misallocation of talent, misallocation at the top of the earnings distribution may have a disproportionately large effect on overall production efficiency, hampering economic growth (Hsieh et al. 2019). Third, top earners are key actors in political and economic decisions that affect society at large, and gender disparities at the top of the earnings distribution may therefore be indicative of a lack of female influence on these decisions.

Our method extends Atkinson et al. (2018) and exploits that both male and female top earnings are Pareto distributed. Specifically, we show that the difference between the male and female top-earnings distributions can be summarized by two parameters: A topearnings gender gap and a glass-ceiling coefficient. The top-earnings gender gap is a level difference between the distributions and captures the earnings difference between men and women at a given position in the earnings distribution. The glass-ceiling coefficient is a shape difference between the distributions and describes the rate at which women become increasingly underrepresented further up in the earnings distribution. We show how this two-parameter representation corresponds to a more general measure of between-group inequality proposed by LeBreton et al. (2012). We also show that the representation corresponds to an analytically convenient tax schedule levied on female earnings, which may be useful when calibrating structural models of top-earnings gender disparities.

We use administrative earnings data from Denmark for the period 1980-2013 to document the evolution of the top-earnings gender gap and the glass-ceiling coefficient. Similar to the average-earnings gender gap, the top-earnings gender gap has fallen gradually over the period. More surprisingly, there has been no change in the glass-ceiling coefficient over this period. Although the top earnings of women have approached that of men, the

\footnotetext{
${ }^{1}$ Similar and related facts for Denmark are reported in Gallen et al. (2019).

${ }^{2}$ For example, Bertrand (2018) writes that "women remain as of today underrepresented in the upper part of the earnings distribution" and that this phenomenon "is often referred to as the glass ceiling", while Blau and Kahn (2017) write that "there was a relatively large gender gap at the top of the distribution" and that "the wage gap fell more slowly (...) at the top than at other portions of the distribution. These two patterns suggest the notion of a 'glass ceiling.' "

${ }^{3}$ Three recent papers that share the ambition of establishing stylized facts regarding gender differences in top earnings, although focusing on different measures and aspects, are Albrecht et al. (2015) and Boschini et al. (2020), who both study Sweden, as well as Guvenen et al. (2014) who study the US.
} 


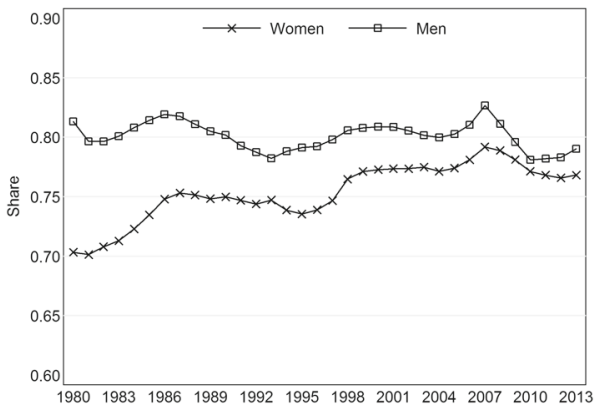

a

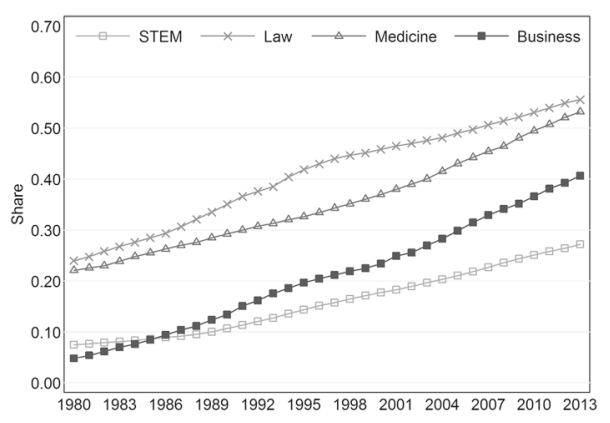

C



b

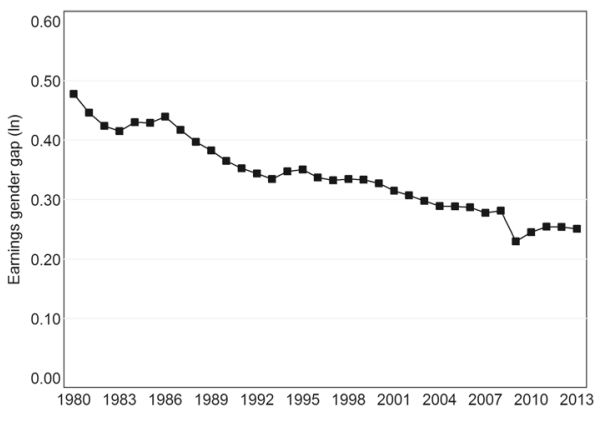

d

Fig. 1 Gender disparities in the labor market, based on the full sample of annual gross earnings of Danish workers aged 18-64. The gender earnings gap equals the log difference between male and female average annual earnings. A person is defined as participating in a given year if he or she has positive gross earnings in that year. A person is defined as a part-time worker if he or she works less than 27 hours per week. For a full data description, see Section 3.1. a Labor force participation by gender. b The share of part-time workers among participants by gender. c Female education shares. $\mathbf{d}$ The gender earnings gap

probability that a woman in the top $1 \%$ also belongs to the top $0.1 \%$ of the earnings distribution has been remarkably stable since 1980 .

We also document the evolution of the two measures over the life cycle and how they have evolved within and across high-earning educational groups. We follow cohorts through the life cycle and compute the cohort-specific top-earnings gender gap and glassceiling coefficient. The cohort top-earnings gender gap is comparatively small early in life, increasing until around age 40, and then decreasing. This result is in line with previous findings regarding the average earnings gap (Albrecht et al. 2018). In contrast, the cohort glass-ceiling coefficient is steadily increasing throughout the life cycle. To the best of our knowledge, this is a new empirical finding. We compute the top-earnings gender gap and the glass-ceiling coefficient separately for business majors, STEM majors, medical doctors and law majors. There is substantial variation in both the top-earnings gender gap and the glassceiling coefficient across these educational groups. However, apart from business majors, where the top-earnings gender gap has steadily increased over the period, there are no clear time trends within these groups.

Overall, our analysis suggests that the factors affecting the top-earnings gender gap are likely different from those affecting the glass-ceiling coefficient, given the different behavior of the two in the data. We conclude the paper with a discussion of factors which may account for our findings and relate to the literature estimating gender-specific causal effects 

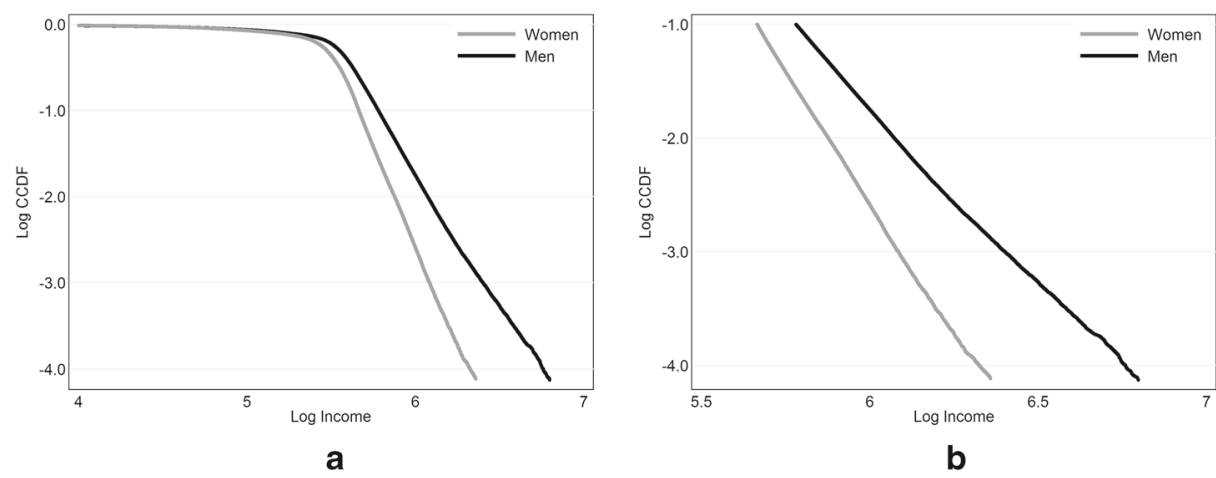

Fig. 2 Log-log plot of the countercumulative distribution of yearly earnings for both men and women, Denmark 2009. Earnings are measured in Danish kroner. For the data description, see Section 3.1. The x-axis is $\log$ (base 10) earnings. A value of six therefore corresponds to 1,000,000 DKK ( 150,000 USD). The charts are based on bins of five individuals. a Full sample. b Top 10\% sample

on earnings. In particular, we point to the importance of understanding the gender differences in earnings growth across careers, and relate this to the literature uncovering gender differences in work-place dynamics.

\section{Describing top-earnings gender disparities using Pareto distributions}

It is well-known that top earnings are described well by Pareto distributions (Gabaix 2016a). ${ }^{4}$ Figure 2 shows base $10 \log$-log plots of the countercumulative distribution function (CCDF) of yearly gross earnings for men and women for the year 2009, using the full sample of all Danish workers aged 18-64 and the top 10\% subsample, respectively. For the top $10 \%$ samples, the countercumulative distributions are virtually straight lines, indicating Pareto distributions $F_{i}(y)=1-L_{i} y^{-\alpha_{i}}$ where $i \in\{m, w\}$ :

$$
\begin{aligned}
& F_{i}(y)=1-L_{i} y^{-\alpha_{i}} \\
\Leftrightarrow & \log \left(1-F_{i}(y)\right)=\log L_{i}-\alpha_{i} \log y .
\end{aligned}
$$

Because top earnings are well described by Pareto distributions, we can summarize how the distributions of male and female top earnings differ with two parameters only. The male and female Pareto distributions in Fig. $2 \mathrm{~b}$ differ in their level and in their slopes. The difference in the level, $\delta \equiv \log L_{m}-\log L_{w}$, measures the horizontal distance between the two lines in Fig. 2 at the point where $\log (1-F(y))=-1$, i.e., it measures the earnings gap between the woman and the man at the 90th percentile of their respective gender-specific distributions. In the figure, this distance is approximately 0.13 base $10 \log$ points, meaning that a man in the 90th percentile earns approximately $10^{0.13} \approx 35 \%$ more than a woman in the 90th percentile. Note that in terms of summarizing the difference between male and female top earnings, the choice to evaluate the gap at the 90th percentile is arbitrary, one

\footnotetext{
${ }^{4}$ Throughout this paper, we will refer to top earnings as earnings higher than the 90 th percentile of a given distribution. While this definition is line with much of the literature on top incomes, the exact cutoff is, of course, arbitrary.
} 
could measure a top-earnings gender gap at the 95th percentile or the 99th percentile just as well.

As for the difference in the slopes, the steeper line for women means that the tail of the earnings distribution of women is thinner than the tail of the earnings distribution of men. Atkinson et al. (2018) note that the ratio of these slopes is a natural measure of the glass ceiling as it captures the increased scarcity of women as we move further up the earnings distribution. Following their reasoning, we define $\gamma \equiv \alpha_{f} / \alpha_{m}-1$ and call it the glass-ceiling coefficient.

Proposition 2.1 shows how to interpret the glass-ceiling coefficient. It describes how, for example, the share of women in the top $0.1 \%$ relates to the share of women in the top $1 \%$. If the glass-ceiling coefficient is 0 , then the share of women in the top $0.1 \%$ is equal to the share of women in the top $1 \%$, but if the glass-ceiling coefficient is positive, then the share is lower. Note that this way of measuring the glass ceiling does not depend on an arbitrary choice of a cutoff, like the definition of the top-earnings gender gap $\delta$ did.

Proposition 2.1 Let male earnings follow a Pareto distribution $F_{m}(y)=1-\underline{y}_{m}^{\alpha_{m}} y^{-\alpha_{m}}$ and let female earnings follow a Pareto distribution $F_{w}(y)=1-\underline{y}_{w}^{\alpha_{w}} y^{-\alpha_{w}}$. Denote the glass ceiling coefficient $\gamma=\alpha_{w} / \alpha_{m}-1$. Then,

$$
\frac{\text { Share women in top } q_{1}}{\text { Share women in top } q_{0}}=\left(\frac{q_{1}}{q_{0}}\right)^{\gamma}\left(\frac{\text { Share men in top } q_{1}}{\text { Share men in top } q_{0}}\right)^{1+\gamma} \text {. }
$$

Proof Let the cutoff for top $q_{i}$ be $y_{i}$. The share of women in the top $q_{i}$ is given by $\frac{y_{w}^{\alpha_{w}} y_{i}^{-\alpha_{w}}}{q_{i}} \times$ $\frac{N_{w}}{N}$, where $N_{w}$ and $N$ is the number of women and the total population, respectively. The ratio of the two shares is $\frac{\text { Share women in top } q_{1}}{\text { Share women in top } q_{0}}=\frac{\frac{\underline{y}_{w}^{\alpha} y_{1}^{-\alpha}}{q_{1}}}{\frac{\underline{\underline{y}} w_{w} y_{0}^{-\alpha_{w}}}{q_{0}}}=\frac{q_{0}}{q_{1}}\left(\frac{y_{1}}{y_{0}}\right)^{-\alpha_{w}}$. Similarly, we have $\frac{\text { Share men in top } q_{1}}{\text { Share men in top } q_{0}}=\frac{q_{0}}{q_{1}}\left(\frac{y_{1}}{y_{0}}\right)^{-\alpha_{m}}$. Put the two together, and we get

$$
\frac{\text { Share women in top } q_{1}}{\text { Share women in top } q_{0}}=\left(\frac{q_{1}}{q_{0}}\right)^{\alpha_{w} / \alpha_{m}-1}\left(\frac{\text { Share men in top } q_{1}}{\text { Share men in top } q_{0}}\right)^{\alpha_{w} / \alpha_{m}} \text {. }
$$

In the Danish data, men are overrepresented in the top of the earnings distribution. In 2013, the share of men in top 10,1 and $0.1 \%$ is 75,88 and $93 \%$, respectively. If men are vastly overrepresented in the top, then the ratio $\frac{\text { Share men in top } q_{1}}{\text { Share men in top } q_{0}}$ is approximately 1 and we get the approximation

$$
\frac{\text { Share women in top } q_{1}}{\text { Share women in top } q_{0}} \approx\left(\frac{q_{1}}{q_{0}}\right)^{\gamma} .
$$

For example, if $\gamma=0.4$, as is the case for the lines in Fig. $2 b$, then the share of women in the top $0.1 \%$ is about $40 \%$ of the share of women in the top $1 \%$, since $\left(\frac{0.01}{0.1}\right)^{0.4} \approx 0.4 .^{5}$

\footnotetext{
${ }^{5}$ In addition to describing the underrepresentation of women in some top share conditional on their representation in some broader top share, the glass-ceiling coefficient also describes the underrepresentation of women above some earnings cutoff given their representation in some lower earnings cutoff. More specifi-


$\left(\frac{\# \text { men with earnings } \geq y_{1}}{\# \text { men with earnings } \geq y_{0}}\right)^{1+\gamma}$.
} 
The top-earnings gender gap and the glass-ceiling coefficient summarize what LeBreton et al. (2012) call the first-order discrimination curve when restricted to top earners, which is a more general description of between-group inequality. ${ }^{6}$ For two groups, given the earnings of percentile $t$ in the earnings distribution of group 2 (e.g., women), this curve tells you which percentile $\Phi^{1}(t)$ of group 1 (e.g., men) earns the same amount. When the analysis is restricted to top earners such that male and female earnings are Pareto distributed, the curve $\Phi^{1}(t)$ is a function of the Pareto tail parameter of male earnings $\alpha_{m}$, the top-earners gender gap $\delta$ and the glass-ceiling coefficient $\gamma$. In other words, keeping overall top-earner inequality constant (as captured by $\alpha_{m}$ ), the top-earner gender gap $\delta$ and the glass-ceiling coefficient $\gamma$ summarize the entire top-earner first-order discrimination curve. ${ }^{7}$

The gender inequality in top earnings may be interpreted as if there is a female-specific tax on earnings. Because the underlying earnings distribution is Pareto, the implied tax schedule has a convenient functional form, commonly used in public finance following Feldstein (1969). The glass-ceiling coefficient is naturally interpreted as a measure of tax progressivity, the convexity of the tax schedule, and conditional on this tax progressivity, the top-earnings gender gap is naturally interpreted as the determinant of the tax level:

Proposition 2.2 (Tax interpretation) Let both male and female top earning potential $Z$ be drawn from a distribution with $C D F F(z)=1-\underline{z}^{\alpha} z^{-\alpha}$. Let male earnings equal the earning potential, $Y_{m}=Z$ and let female earnings be subject to a tax scheme $Y_{w}=\left(1-\tau_{0}\right) Z^{1-\tau_{1}}$. Then, the glass-ceiling coefficient is $\gamma=\tau_{1} /\left(1-\tau_{1}\right)$ and the top-earnings gender gap at the baseline level of earnings potential $\underline{z}$ is $\delta=-\gamma \log \left(1-\tau_{0}\right)$.

Proof The distribution of earnings for women is given by

$$
\begin{aligned}
F_{w}(y) & =P\left(Y_{w} \leq y\right)=P\left(\left(1-\tau_{0}\right) Z^{1-\tau_{1}} \leq y\right)=P\left(Z \leq\left(\frac{y}{1-\tau_{0}}\right)^{1 /\left(1-\tau_{1}\right)}\right)= \\
& =1-\left(1-\tau_{0}\right)^{\alpha /\left(1-\tau_{1}\right)} \underline{z}^{\alpha} y^{-\alpha /\left(1-\tau_{1}\right)} .
\end{aligned}
$$

Therefore, the glass-ceiling coefficient is $1 /\left(1-\tau_{1}\right)-1=\tau_{1} /\left(1-\tau_{1}\right)$. The top-earner gender gap is given by the log difference between the level of the two earnings distributions,

$$
\delta=\log (\underline{z})-\log \left(\left(1-\tau_{0}\right)^{1 /\left(1-\tau_{1}\right)} \underline{z}\right)=-\gamma \log \left(1-\tau_{0}\right) .
$$

This result is useful because it links the study of gender disparities in top earnings to the structural literature on taxation, human capital investment, and labor market outcomes. The influential studies by Benabou (2002) and Heathcote et al. (2017) consider optimal tax design taking into account that progressive taxes distort human capital investment, exploiting the analytical convenience of the same tax schedule as in Proposition 2.2. Similar frameworks may be used to study positive questions regarding top-earnings gender disparities, for example how exogenous distortions (e.g., discrimination) may explain gender differences in human-capital investment. From this perspective, one may hypothesize

\footnotetext{
${ }^{6}$ Lambert and Subramanian (2014) use this curve to describe between-group inequality at the bottom of the earnings distribution. See also Handcock and Morris (2006).

${ }^{7}$ Define the first-order discrimination curve $\Phi^{1}:[0,1] \rightarrow[0,1]$ as $\Phi^{1}(t)=F_{m}\left(F_{w}^{-1}(t)\right)$ where $F_{m}$ and $F_{w}$ are the cumulative distribution functions of male and female earnings. If $F_{m}$ and $F_{w}$ are both Pareto distributed, then the first-order discrimination curve for top earners is $\Phi^{1}(t)=\max \left\{0,1-\exp \left(\alpha_{m} \delta\right)(1-\right.$ $\left.t)^{1 /(1+\gamma)}\right\}$.
} 
that the glass-ceiling coefficient $\gamma$ is a key moment in determining the relative disincentive for women in making such investments. Moreover, and more generally, matching the glass-ceiling coefficient is a natural target when calibrating structural models of labor supply, occupational choice, and skill investment when applied to study gender differences. For examples of such models, see, e.g., Albanesi and Olivetti (2009), Guner et al. (2012) and Fernández and Wong (2014).

\section{Computing the top-earnings gender gap and glass-ceiling coefficient for Denmark 1980-2013}

In the empirical analysis, we study gender disparities in top labor earnings in Denmark. Specifically, we track the evolution of the top-earnings gender gap and the glass-ceiling coefficient in Denmark over the period 1980-2013, both in the aggregate and also across the life cycle and educational groups. This analysis complements Atkinson et al. (2018), who study the evolution of the aggregate glass-ceiling coefficient for total income (including capital income and self-employment income) in several countries, without comparing it with the top-income gender gap.

We compute the top-earnings gender gap as the difference between the male and female $\log$ earnings at the 90th percentiles. To ease interpretation, we report this difference in natural log points. We compute the glass-ceiling coefficient by first fitting a Pareto distribution, using maximum likelihood, to the top $10 \%$ of the earnings distribution for men and women separately, and then computing the glass-ceiling coefficient from the shape parameters of the two fitted Pareto distributions, $\gamma=\alpha_{f} / \alpha_{m}-1$.

\subsection{Data}

Data sources In our analysis, we combine three Danish datasets on the population, earnings, and education level. The point of departure for our analysis is the Danish Civil Registration System ${ }^{8}$ for the full population in Denmark 1980 to 2013. The register includes all individuals with residence in Denmark on December 31st of a given year. From this registry, we obtain information about the date of birth and gender. We link these individuals to the income and education registries using the unique personal identification number. From the income registry, we obtain information on earnings, based on tax records. From the education registry, we obtain data on the highest completed educational degree. Information on educations completed before 1970 is based on a census compiled in November 1970 and third-party reports. Information on degrees completed after 1970 is based on information reported directly from the institutions (for degrees completed in Denmark) and surveys (for degrees completed outside Denmark).

Earnings variables From the income registry, we create a gross earnings variable that includes taxable and nontaxable income from employment, the value of fringe benefits, the value of stock options, and severance pay. Income from self-employment is not included.

We present our results using two different earnings concepts. Specifically, we use a oneyear and a five-year forward-looking moving average earnings concept. The former has the advantage of allowing us to include more years and have a less restricted population.

\footnotetext{
${ }^{8}$ In Danish: "Det Centrale Personregister" or "CPR-Registret".
} 
The latter allows us to ignore yearly fluctuations, but requires restricting the sample to individuals observed in at least five consecutive years.

Labor force participation Labor force participation is defined by having positive earnings in a given calendar year, using the earnings concept described above. Part-time work is defined as working less than 27 hours per week, where the hours of work are imputed based on the contributions to the Labor Market Supplementary Pension Fund (ATP).

Educational classifications We classify individuals according to the highest completed education on October 1 in the given year implying that the highest educational degree is varying over time. The educational degrees are classified by field and level according to the International Standard Classification of Education (ISCED) (UNESCO 2014). The highest degree is identified based on the ranking within the ISCED.

Sample selection We restrict the sample to individuals with positive earnings who are between 18 to 64 years old at the beginning of the year. We impose no further sample restrictions.

\subsection{The top-earnings gender gap and glass-ceiling coefficient}

In Figure 3, we show the evolution of the top-earnings gender gap and glass-ceiling coefficient from 1980 to 2013, both for one-year earnings and five-year earnings. While the top-earnings gender gap has decreased, the glass-ceiling coefficient has remained stable.

The top-earnings gender gap As seen from Panels Fig. 3a and b, the top-earnings gender gap has steadily decreased from around $0.4 \mathrm{log}$ points in 1980 to $0.3 \mathrm{log}$ points in 2013 . In 1980, a man at the 90th percentile of the men's earnings distribution earned $e^{0.4}=49 \%$ more than a woman at the 90th percentile of the women's earning distribution. By 2013, this gap had decreased to $e^{0.3}=35 \%$.

The glass-ceiling coefficient As seen from the bottom Panels $3 \mathrm{c}$ and $3 \mathrm{~d}$, the glass-ceiling coefficient has fluctuated around 0.4 without trend over the sample period.

What does a glass-ceiling coefficient of 0.4 mean? Recall the approximation from Section 2,

$$
\frac{\text { Share women in top } 1 \%}{\text { Share women in top } 10 \%} \approx \frac{\text { Share women in top } 0.1 \%}{\text { Share women in top } 1 \%} \approx 0.1^{\gamma} \approx 0.40 \text {. }
$$

Thus, a glass ceiling coefficient of 0.4 means that the share of women in the top $0.1 \%$ is around 0.4 of the share of women in the top $1 \%$, which in turn is around 0.4 of the share of women in the top $10 \%$. The stability of the glass-ceiling coefficient across time means that these ratios in 2013 were the same as in 1980.

How should we interpret the combination of a falling gender gap and a stable glassceiling coefficient? This joint observation tells us that although the earnings difference between men and women at the 90th percentile has decreased, the representation of women in the very top of the earnings distribution conditional on being in the top of the earnings distribution (e.g, $\frac{\text { Share women in top } 0.1 \%}{\text { Share women in top } 1 \%}$ ) has remained stable. The gradual decline of the topearnings gender gap is consistent with the gradual decline of the total earnings gender gap. It is also likely that the factors contributing to the decline in the total earnings gender gap, e.g., the increasing share of women participating in the labor market, working full time, and 

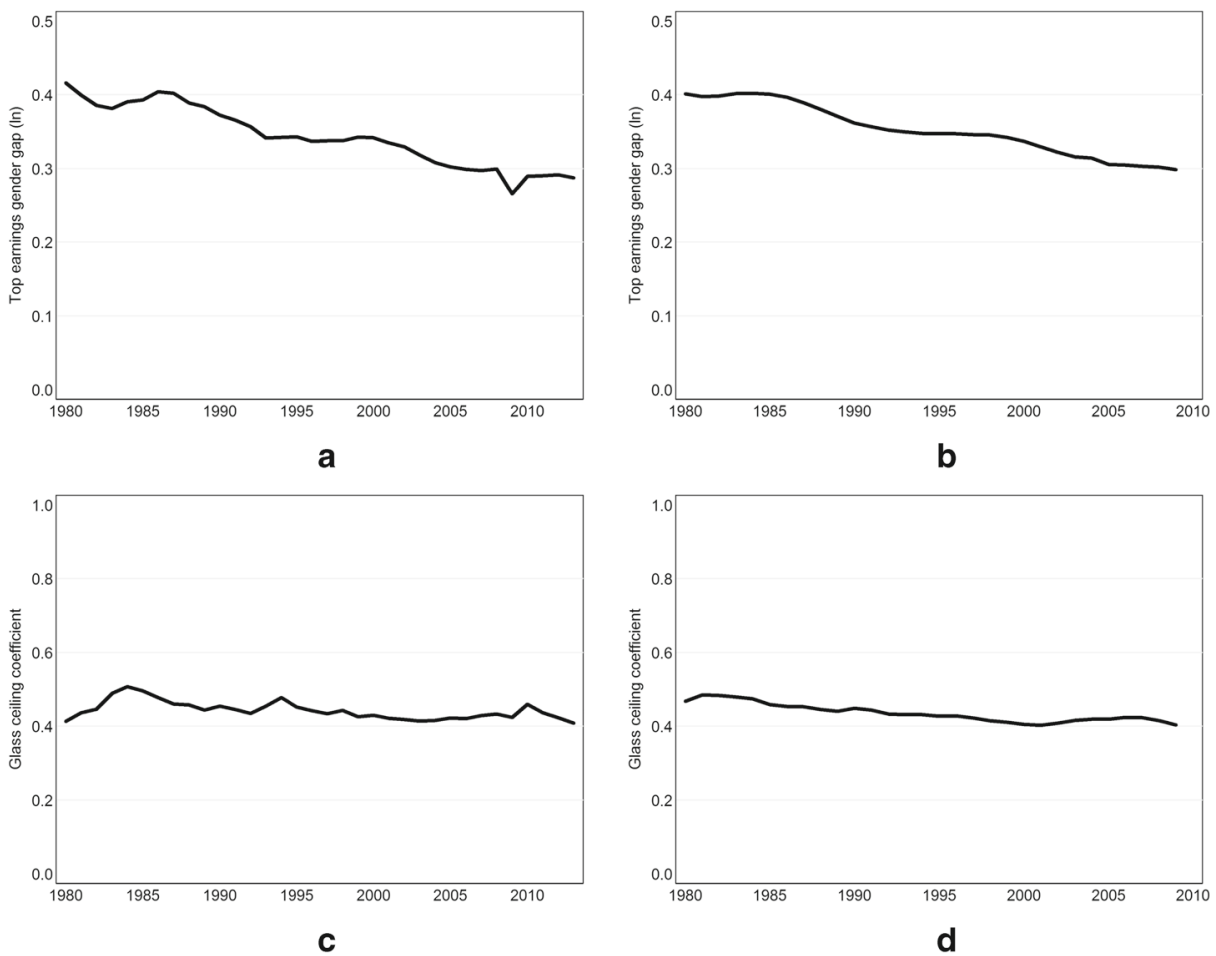

Fig. 3 The evolution of the top-earnings gender gap and glass-ceiling coefficient for Denmark 1980-2013. Five-year earnings are computed as a forward-looking moving average, see Section 3.1. a The top-earnings gender gap, 1-year earnings. b The top-earnings gender gap, 5-year earnings. c The glass-ceiling coefficient, 1 -year earnings. d The glass-ceiling coefficient, 5-year earnings

entering high-earning professions, also explain the development of the top-earnings gender gap. From this perspective, the stability of the glass-ceiling coefficient is a surprising result. Although we do not present any causal evidence in this paper, a natural conjecture is that the aforementioned changes in the labor market that have taken place over the last decades have not been effective in advancing the promotion of women from being top earners to reaching the very top.

\subsection{Results over the life cycle}

We now turn to the life-cycle dimension of top-earnings gender inequality. From the previous literature, we know that both the gaps in total and top earnings between men and women grow up to around age 40 see, e.g., Manning and Swaffield (2008) and Albrecht et al. (2018). We also know that the Pareto tail parameter $\alpha$ of the total earnings distribution increases with age (Badel et al. 2018). Less is known about the evolution of the glass ceiling over the life cycle.

In Fig. 4, we plot the evolution of the top-earnings gender gap and glass-ceiling coefficient for six cohorts over their working life. To gain precision, we compute the top-earnings gender gap and glass-ceiling coefficient based on data for three years around each age level. For example, the top-earnings gender gap at age 40 is computed from the pooled sample of all earnings at ages 39,40 , and 41 of any given cohort. 




a

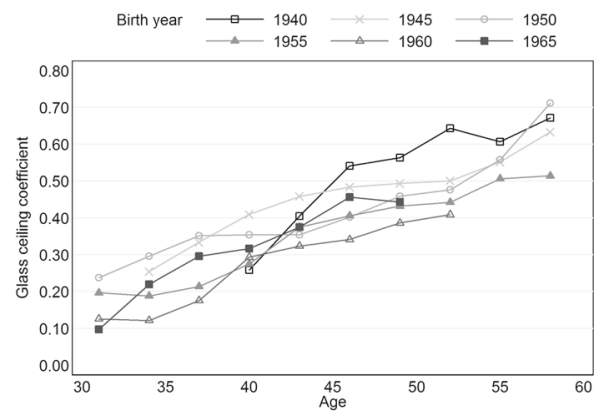

C

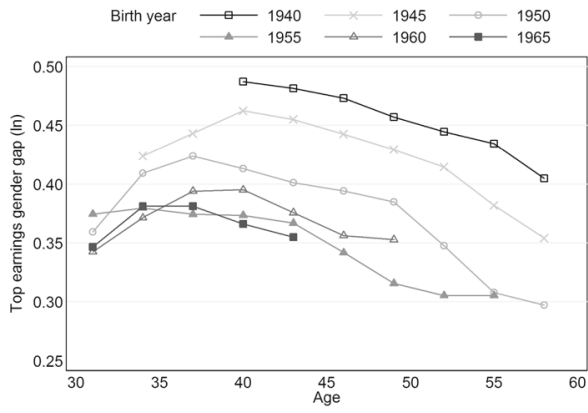

b

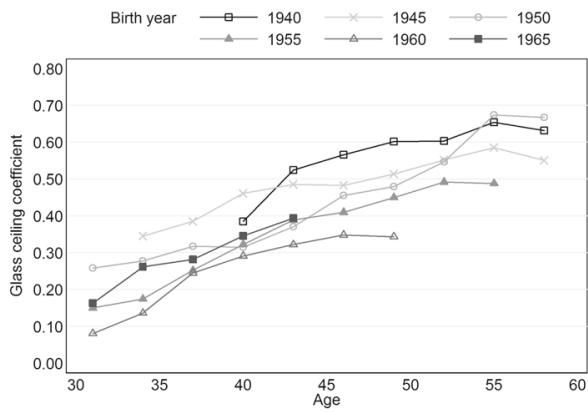

d

Fig. 4 The evolution of the top-earnings gender gap and the glass-ceiling coefficient over the life cycle in Denmark 1980-2013. Five-year earnings is computed as a forward looking moving average, see Section 3.1. a Top-earnings gender gap, 1-year earnings. b Top-earnings gender gap, 5-year earnings. c Glass-ceiling coefficient, 1-year earnings. d Glass-ceiling coefficient, 5-year earnings

The cohort top-earnings gender gap The evolution of the top-earnings gender gaps over the life cycle for the six different cohorts, for one-year and five-year earnings respectively, are displayed in Panels $4 \mathrm{a}$ and $4 \mathrm{~b}$. The top-earnings gender gap is positive and humped shaped over the life cycle. We can follow the cohort born in 1950 throughout their entire working life. At age 30-32, the top-earnings gender gap for the cohort is 0.34 log points (40\%). The cohort top-earnings gender gap is increasing until age 36-38, peaking at $0.42 \mathrm{log}$ points (52\%). After age 40, the top-earnings gender gap decreases and before retirement, the top-earnings gender gap is around $0.28 \log$ points (32\%).

We cannot follow the other cohorts throughout their entire working life, but the qualitative life-cycle pattern is similar for the ages we do observe. The level of the top-earnings gender gap is higher for the early cohorts, with a peak of $0.5 \mathrm{log}$ points for the 1940 cohort compared to the 1965 cohort with a peak below $0.4 \log$ points. This is consistent with the gradual decline of the aggregate top-earnings gender gap in Fig. $3 \mathrm{a}$ and $\mathrm{b}$.

The cohort glass-ceiling coefficient The evolution of the glass-ceiling coefficients over the life-cycle for the six different cohorts, for one-year and five-year earnings respectively, are displayed in Panels 4c and 4d. In contrast to the evolution of the top-earnings gender gap, the glass-ceiling coefficient is steadily increasing over the life cycle. It is also stable across cohorts, consistent with the stability of the aggregate glass-ceiling coefficient in Fig. 3c and d. For five-year earnings, the glass ceiling levels off or drops at the age 58-60. This, 
however, likely reflects the effect of retirement, as five-year earnings are computed as a five-year forward-moving average.

For one-year earnings, the 1950 cohort has a glass-ceiling coefficient of 0.24 at age 30-32, which increases throughout their working life to a level of 0.64 at age 63-65. The lifecycle evolution of the glass-ceiling coefficient is similar for the other cohorts. Quantifying this, a glass-ceiling coefficient of 0.24 means that women are underrepresented in the top $0.1 \%$ by a factor $0.1^{0.24}=0.58$ given their representation in the top $1 \%$. Specifically, this means that the share of women in the top $0.1 \%$ was around 0.58 of the share of women in the top $1 \%$, which in turn is around 0.58 of the share of women in the top $10 \%$. A glassceiling coefficient of 0.64 means that the relative representation of women when moving up the same top shares falls off at the rate of $0.1^{0.64}=0.23$.

Similar to the evolution in the aggregate, the evolution of the top-earnings gender gap over the life cycle contrasts with that of the glass-ceiling coefficient. While the two measures of top-earnings gender disparities grow hand-in-hand until age 40, they diverge thereafter. This suggests that after age 40, the two measures should be treated as separate phenomena, and that the forces affecting the life-cycle dynamics of the top-earnings gender gap may be different than those affecting the glass-ceiling coefficient.

\subsection{Results across educational groups}

We investigate the evolution of the top-earnings gender gap and glass ceiling coefficient across four high-earning university-degree education groups: business, medicine, STEM, and law majors. These education groups are particularly interesting due to their overrepresentation among top earners. Several studies have documented and investigated the causes of gender disparities in these groups. For example, see Bertrand et al. (2010) on the gender gap for MBA graduates, Azmat and Ferrer (2017) for lawyers, Jena et al. (2016) for medical doctors and Beede et al. (2011) for STEM graduates. An earlier literature has also documented the heterogeneity of gender gaps across university-level education groups, see, e.g., Black et al. (2008). To the best of our knowledge, no study has documented the heterogeneity and evolution of a measure of the glass ceiling across education groups.

We identify a person as having a university degree if the person holds a bachelor degree or higher (ISCED level degree of 6 or higher). The education groups are then identified using 4-digit level ISCED field codes. ${ }^{9}$ In Fig. 5, we show the education group shares in the top $1 \%$ and top $10 \%$ of the earnings distribution by gender and year. Together, in 2013, these groups constitute $36.4(28.7) \%$ of the population of top 1(10)\% earners. Compared to women, male top earners are more likely to be STEM and business majors, whereas female top earners are more likely to be medicine majors.

In Fig. 6, we display the evolution of the top-earnings gender gap and the glass-ceiling coefficient for the four education groups.

The top-earnings gender gap As seen from the top panels of Fig. 6, there is considerable variation in the top-earnings gender gap across the educational groups. Focusing on one-year earnings in 1980, the lowest gaps are found within medicine. Here, the gap is below

\footnotetext{
${ }^{9}$ More specifically, in our classification, a business major has a degree in a field within "accounting and taxation", "finance, banking and insurance", "management and administration" or "marketing and advertising". A STEM major has a degree in a field within "natural sciences, mathematics and statistics", "information technologies and communication technologies" or "engineering and engineering trades". Law and Medicine have their own separate ISCED codes.
} 


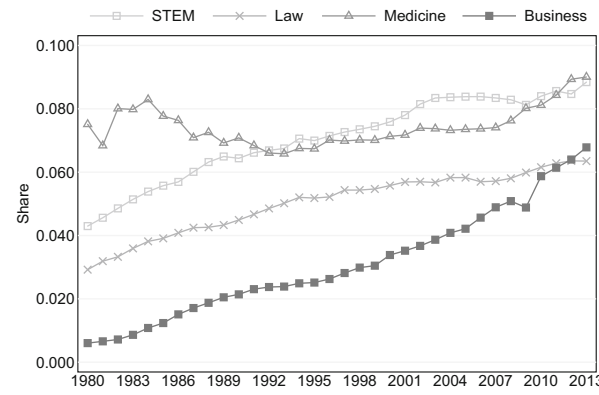

a



C



b

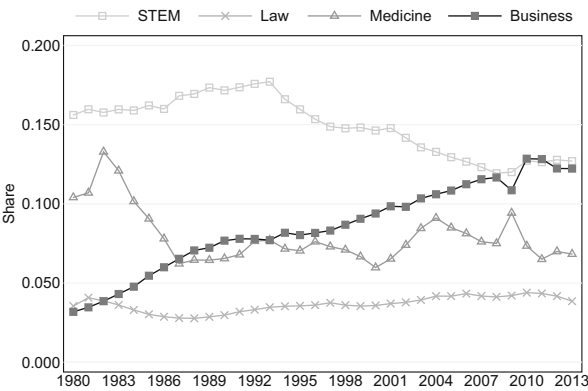

d

Fig. 5 Education shares in the top $1 \%$ and top $10 \%$ by gender \& degree. a Women - top $10 \%$. b Men - top $10 \%$. c Women - top $1 \%$. d Men - top $1 \%$

$0.2 \log$ points $(22 \%)$. In the other three groups, the gap was around $0.3 \log$ points (35\%). In contrast to the stable decline in the aggregate top-earnings gender gap (Fig. 3), the gap has not declined within any of these groups over the period. For STEM and law majors, it has remained largely constant. For medicine, it has increased and converged towards the levels found in law and STEM. For business majors, it has increased dramatically. In 2013, the top-earnings gender gap was $0.5 \log$ points $(65 \%)$, about twice as high as the level found in medicine and STEM. These patterns are largely the same for five-year earnings.

The glass-ceiling coefficient In the bottom panels of Fig. 6, we display the evolution of the glass-ceiling coefficient. Similar to education-specific top-earnings gender gaps, there is also considerable variation here. In contrast, however, there is no positive trend within any education group over time. Given that sample sizes are considerably smaller here than in the previous analyses, the graphs are much smoother for five-year than for one-year earnings. Focusing on five-year earnings, the lowest level of the glass-ceiling coefficient has been within medicine throughout the period, around 0.2 since 1995. This level means that the share of female medicine majors in the top $0.1 \%$ is around $0.1^{0.22}=0.63$ of the share of female medicine majors in the top $1 \%$, which in turn is around 0.63 of the share of female medicine majors in the top $10 \%$. For the other three groups, the glass-ceiling coefficients have come down from very high levels in the early 1980s until today. In 2013, they lie all within the range $[0.35-0.55]$.

Regarding the relationship between the top-earnings gender gap and the glass-ceiling coefficient, the cross-sectional and time-series variation point in different directions. For the more recent years, the data display a positive correlation between the the glass-ceiling 


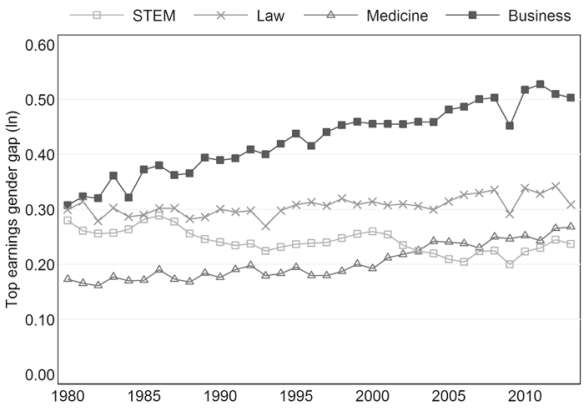

a

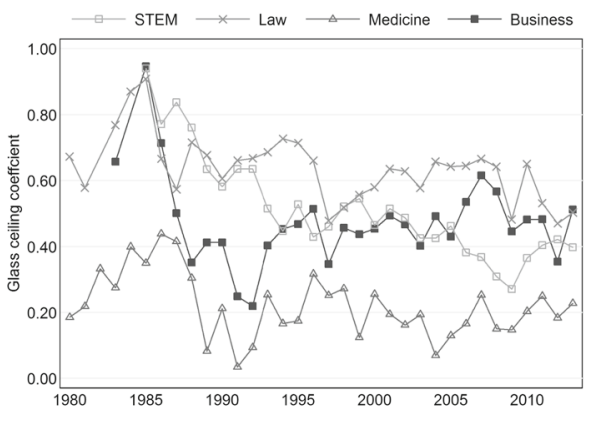

C



b

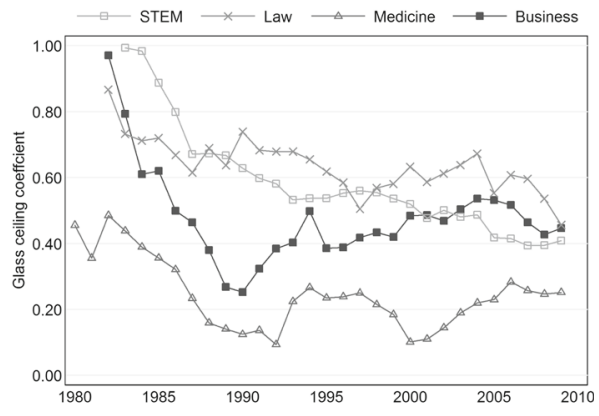

d

Fig. 6 The evolution of the top-earnings gender gap and the glass-ceiling coefficient for Denmark 19802013, by education. Five-year earnings is computed as a forward looking moving average, see Section 3.1. a Top-earnings gender gap, 1-year earnings. b Top-earnings gender gap, 5-year earnings. c Glass-ceiling coefficient, 1-year earnings. d Glass-ceiling coefficient, 5-year earnings

coefficient and the top-earnings gender gap across educational groups. In 2013, medicine and STEM display the lowest values in both measures, whereas business and law display the highest. Over time, however, the top-earnings gender gap has been steadily increasing for business and medicine majors while there is no clear trend in the glass-ceiling coefficient beyond the decline during the eighties. Taken together, this again suggests that the forces shaping the glass-ceiling coefficient are likely different from those determining the topearnings gender gap.

\section{Discussion}

Building on the insight of Atkinson et al. (2018) and using that top earnings are approximately Pareto distributed, we have shown that top-earnings gender disparities can be summarized by two parameters: the top-earnings gender gap and the glass-ceiling coefficient. The top-earnings gender gap is a level difference between the distributions and captures the earnings difference between men and women at a given position in the earnings distribution. The glass-ceiling coefficient is a shape difference between the distributions and describes the rate at which women become increasingly underrepresented further up in the earnings distribution. We have also shown that if the top-earning gender disparities are interpreted as being caused by a female-specific tax on earnings, the glass-ceiling coefficient 
measures the progressivity of this tax. Conditional on this tax progressivity, the top-earnings gender gap measures the tax level.

We have used these insights to document a set of facts for top-earning gender disparities in Denmark 1980-2013. The overarching conclusion is that the top-earnings gender gap and the glass-ceiling coefficient display different evolution over time, across the life cycle, and across educational groups, suggesting that they should be treated as separate phenomena.

The aggregate evolution and the life-cycle dynamics of the top-earnings gender gap are in line with what has been documented regarding the total earnings gap in the previous literature. It is natural to conjecture that the same factors governing the dynamics of the total earnings gender gap also account for the dynamics of the top-earnings gender gap. In particular, the increased share of women entering high-earning professions has most likely contributed to the gradual decrease in both measures over time.

The more surprising result is that the dynamics of the glass-ceiling coefficient contrast with the dynamics of the top-earnings gender gap. Indeed, while the top-earnings gender gap has declined during 1980-2013 in Denmark, the glass-ceiling coefficient has been remarkably stable. A key takeaway from this paper is therefore that we cannot assume that the same factors that affect the top-earnings gender gap also affect the glass-ceiling coefficient. A relatively large body of studies has dissected and investigated causal mechanisms for the average-earnings gender gap, and many of the insights seem likely to hold also for top earnings. Less attention has been directed to understanding measures related to the glass-ceiling coefficient. We therefore close the paper with a discussion of what factors may explain a positive glass-ceiling coefficient. ${ }^{10}$

One approach to understanding the sources of cross-sectional income differences is to consider the underlying dynamic income processes that agents face. A simple, but still quite general, point of departure for modeling top earnings processes is a Steindl (1965)-type process (see also Jones and Kim 2018 and Gabaix et al. 2016b), which is consistent with the fact that top earnings are Pareto distributed. In a Steindl process, an individual's earnings start at some initial level and then grow at some rate (which may be subject to stochastic shocks). Furthermore, the individual faces a probability to "fall off the ladder" and restart the earnings process. In steady state, a lower Pareto tail parameter $\alpha$ may either result from a higher average earnings growth or a lower probability of falling off the ladder, but it is not affected by the initial earnings level.

From the perspective of a Steindl process, it is key to investigate gender differences in earnings growth and disruptive career events to understand the glass ceiling, whereas gender heterogeneity in initial earnings levels is of less importance. A potential explanation to why the glass-ceiling coefficient has remained stable despite the increased female presence in high-earning professions, is that this educational development has primarily affected gender differences in top earnings levels while not so much gender differences in top earnings growth.

This could also explain the heterogeneity in the glass-ceiling coefficient that we document across educational groups. Consistent with the high glass-ceiling coefficient that we document among business majors, Bertrand et al. (2010) show that female American MBA graduates have slower career progression owing to more frequent career interruptions and shorter hours worked. Bütikofer et al. (2018) find that childbirth is both associated with a larger fall in earnings and lower earnings growth among business and law majors compared to STEM and medicine majors in Norway. Moreover, Niederle and Vesterlund (2007) show

\footnotetext{
${ }^{10}$ For a related discussion, see Bertrand (2018).
} 
through a laboratory experiment that women select tasks with tournament element less often than men. They note that this result implies that women shy away from competition while men embrace it. Niederle and Vesterlund (2011) provide evidence that differences in willingness to compete stem from men being more overconfident rather than having different risk aversion. Babcock et al. (2017) show in a laboratory setting that women are more likely to volunteer, be asked to volunteer, and accept requests to do tasks with low promotability.

Regarding the life-cycle dynamics, previous research has highlighted the importance of human capital investments and job-search behavior in explaining gender differences in early-career earnings growth, which account for part of the early-career growth in the average-earnings gender gap (Manning and Swaffield 2008; Albrecht et al. 2018). It is plausible that the same factors account for the early-career growth in the top-earnings gender gap and the glass-ceiling coefficient. From this perspective, it is puzzling that the two measures diverge after age 40, which suggests that more research is needed to understand late-career trajectories for men and women. More generally, from the perspective of estimating both structural and statistical earnings processes for men and women, the life-cycle moments in the top-earnings gender gap and the glass-ceiling coefficient are key moments to be matched.

Acknowledgments We are very grateful for comments from the editor, anonymous referees, Arizo Karimi, Oskar Nordström Skans and seminar participants at CBS, IIES, and UC Santa Barbara. All errors are our own. The views herein are those of the authors and should not be attributed to the IMF, its Executive Board, or its management. Funding from Lars Hierta's Foundation and Handelsbanken's Research Foundations is gratefully acknowledged.

Funding Open Access funding provided by Uppsala University.

Open Access This article is licensed under a Creative Commons Attribution 4.0 International License, which permits use, sharing, adaptation, distribution and reproduction in any medium or format, as long as you give appropriate credit to the original author(s) and the source, provide a link to the Creative Commons licence, and indicate if changes were made. The images or other third party material in this article are included in the article's Creative Commons licence, unless indicated otherwise in a credit line to the material. If material is not included in the article's Creative Commons licence and your intended use is not permitted by statutory regulation or exceeds the permitted use, you will need to obtain permission directly from the copyright holder. To view a copy of this licence, visit http://creativecommonshorg/licenses/by/4.0/.

\section{References}

Albanesi, S., Olivetti, C.: Home production, market production and the gender wage gap: Incentives and expectations. Rev. Econ. Dyn. 12(1), 80-107 (2009)

Albrecht, J., Thoursie, P.S., Vroman, S.: Parental leave and the glass ceiling in Sweden. Emerald Group Publishing Limited (2015)

Albrecht, J., Bronson, M.A., Thoursie, P.S., Vroman, S.: The career dynamics of high-skilled women and men: Evidence from Sweden. Eur. Econ. Rev. 105, 83-102 (2018)

Atkinson, A.B., Casarico, A., Voitchovsky, S.: Top Incomes and the Gender Divide. J. Econ. Inequal. 16, 225-256 (2018)

Atkinson, A.B., Piketty, T., Saez, E.: Top incomes in the long run of history. J. Econ. Literat. 49(1), 3-71 (2011)

Azmat, G., Ferrer, R.: Gender Gaps in Performance: Evidence from Young Lawyers. J. Polit. Econ. 125(5), 1306-1355 (2017)

Babcock, L., Recalde, M.P., Vesterlund, L., Weingart, L.: Gender differences in accepting and receiving requests for tasks with low promotability. Amer. Econ. Rev. 107(3), 714-47 (2017) 
Badel, A., Daly, M., Huggett, M., Nybom, M.: Top Earners: Cross-Country Facts. Fed. Reserv. Bank St. Louis Rev. 100(3) (2018)

Beede, D.N., Julian, T.A., Langdon, D., McKittrick, G., Khan, B., Doms, M.E.: Women in STEM: A Gender Gap to Innovation. ESA Issue Brief, US Department of Commerce (2011)

Benabou, R.: Tax and education policy in a heterogeneous-agent economy: What levels of redistribution maximize growth and efficiency? Econometrica 70(2), 481-517 (2002)

Bertrand, M., Goldin, C., Katz, L.F.: Dynamics of the Gender Gap for Young Professionals in the Financial and Corporate Sectors. Amer. Econ. J. Appl. Econ. 2(3), 228-255 (2010)

Bertrand, M.: Coase Lecture - The Glass Ceiling. Economica 85(338), 205-231 (2018)

Black, D.A., Haviland, A.M., Sanders, S.G., Taylor, L.J.: Gender Wage Disparities among the Highly Educated. J. Hum. Resour. 43(3), 630-659 (2008)

Blau, F.D., Kahn, L.M.: Women's work and wages. The new Palgrave dictionary of economics 8, 762-72 (2008)

Blau, F.D., Kahn, L.M.: The Gender Wage Gap: Extent, Trends, and Explanations. J. Econ. Lit. 55(3), 789865 (2017)

Boschini, A., Gunnarsson, K., Roine, J.: Women in top incomes-evidence from sweden 1971-2017. J. Publ. Econ. 181, 104115 (2020)

Bütikofer, A., Jensen, S., Salvanes, K.G.: The role of parenthood on the gender gap among top earners. Eur. Econ. Rev. 109, 103-123 (2018)

Feldstein, M.S.: The Effects of Taxation on Risk Taking. J. Polit. Econ. 77(5), 755-764 (1969)

Fernández, R.s., Wong, J.C.: Divorce risk, wages and working wives: A quantitative life-cycle analysis of female labour force participation. Econ. J. 124(576), 319-358 (2014)

Gabaix, X.: Power Laws in Economics: An Introduction. J. Econ. Perspect. 30(1), 185-206 (2016a)

Gabaix, X., Lasry, J.-M., Lions, P.-L., Moll, B.: The dynamics of inequality. Econometrica 84(6), 2071-2111 (2016b)

Gallen, Y., Lesner, R.V., Vejlin, R.: The labor market gender gap in denmark: Sorting out the past 30 years. Labour Econ. 56, 58-67 (2019)

Guner, N., Kaygusuz, R., Ventura, G.: Taxation and household labor supply. Rev. Econ. Stud. 79(3), 11131149 (2012)

Guvenen, F., Kaplan, G., Song, J.: The glass ceiling and the paper floor: Gender differences among top earners, 1981-2012. Technical report, National Bureau of Economic Research (2014)

Handcock, M.S., Morris, M.: Relative distribution methods in the social sciences. Springer Science \& Business Media (2006)

Heathcote, J., Storesletten, K., Violante, G.L.: Optimal tax progressivity: An analytical framework. Q. J. Econ. 132(4), 1693-1754 (2017)

Hsieh, C.-T., Hurst, E., Jones, C.I., Klenow, P.J.: The allocation of talent and us economic growth. Econometrica 87(5), 1439-1474 (2019)

Jena, A.B., Olenski, A.R., Blumenthal, D.M.: Sex Differences in Physician Salary in US Public Medical Schools. JAMA Intern. Med. 176(9), 1294 (2016)

Jones, C.I., Kim, J.: A schumpeterian model of top income inequality. J. Polit. Econ. 126(5), 1785-1826 (2018)

Lambert, P.J., Subramanian, S.: Disparities in socio-economic outcomes: some positive propositions and their normative implications. Soc. Choice Welf. 43(3), 565-576 (2014)

LeBreton, M., Michelangeli, A., Peluso, E.: A stochastic dominance approach to the measurement of discrimination. J. Econ. Theory 147(4), 1342-1350 (2012)

Manning, A., Swaffield, J.: The Gender Gap in Early-Career Wage Growth. Econ. J. 118(530), 983-1024 (2008)

Niederle, M., Vesterlund, L.: Do women shy away from competition? do men compete too much? Quart. J. Econ. 122(3), 1067-1101 (2007)

Niederle, M., Vesterlund, L.: Gender and competition. Annu. Rev. Econ. 3(1), 601-630 (2011)

Polachek, S.W., Tatsiramos, K., Zimmermann, K.F.: Gender convergence in the labor market. Emerald Group Publishing (2015)

Roine, J., Waldenström, D.: Long-run trends in the distribution of income and wealth. In: Handbook of income distribution, vol. 2, pp. 469-592. Elsevier (2015)

Steindl, J.: Random processes and the growth of firms: A study of the pareto law, vol. 18. Hafner Publishing Company, New York (1965)

UNESCO: ISCED Fields of Education and Training 2013 (ISCED-F 2013). Technical Report. UNESCO Institute for Statistics (2014)

Publisher's note Springer Nature remains neutral with regard to jurisdictional claims in published maps and institutional affiliations. 